\title{
LA TRADUCCIÓN DE ELEMENTOS TEXTUALES EN OBRAS DE ARTE CONTEMPORÁNEO : TENDENCIAS, RETOS Y PROPUESTAS
}

\author{
Translating Textual Elements in Contemporary Artworks: \\ Trends, Challenges, Proposals \\ TRAdUCTION D'ÉlÉMENTS TEXTUELS DANS DES OEUVRES D'ART CONTEMPORAIN : \\ DES TENDANCES, DÉFIS ET PROPOSITIONS
}

\author{
Cristina A. Huertas Abril \\ Profesora titular, Departamento de \\ Filologías Inglesa y Alemana, Facultad \\ de Ciencias de la Educación. Universi- \\ dad de Córdoba, España. \\ Avda. San Alberto Magno s/n. \\ 14071 Córdoba, España. \\ cristina.huertas@uco.es \\ http://orcid. \\ org/0000-0002-9057-5224
}

\section{Rocío Márquez Garrido}

Máster en Traducción y Nuevas

Tecnologías,

Directora Instituto Superior de Estudios Lingüísticos y Traducción (ISTRAD), Sevilla, España.

Pta. Jerez, 4. 41001 Sevilla, España. rocio.marquez@institutotraduccion.com https://orcid.

org/0000-0003-4609-2230

\begin{abstract}
RESUMEN
A partir del concepto de paratexto de Genette (1987), sobre el cual se desarrolla la teoría de Yuste (2015) acerca de la paratraducción, este trabajo plantea qué ocurre, en lo que a la experiencia del espectador se refiere, cuando una obra de arte presenta elementos textuales en un idioma distinto al del espectador. Para ello, identificamos los elementos verbales que se hallan en obras expuestas en las ferias de arte, con especial atención a la Feria de Arte Contemporáneo de Madrid (ARCO); y dada la ausencia de propuestas de acercamiento lingüístico para el espectador, analizamos la pertinencia de la existencia de la figura del traductor en eventos de este tipo. Con base en una selección de obras en las que el texto participa en la experiencia visual, bien porque constituye una parte fundamental de las mismas o porque resulta en la totalidad de la obra, reflexionamos sobre distintas estrategias posibles para hacerlas accesibles al espectador, permitiéndole tener una experiencia completa de la obra.
\end{abstract}

Palabras clave: paratexto; paratextualidad; paratraducción; traducción; arte contemporáneo; Feria de Arte Contemporáneo de Madrid.

\begin{abstract}
Starting from Genette's (1987) notion of 'paratext', which is the foundation of Yuste's (2015) theory of 'paratranslation', this paper will analyse what happens, as far as the viewer's experience is concerned, when an art work presents textual elements in a language different from the viewer's language. To this end, we will identify the verbal elements included in works exhibited in art fairs, paying special attention to the International Contemporary Art Fair of Madrid (ARCO), and will analyse the adequacy of the translator's figure in events of this sort. From a selection of works in which text forms part of the visual experience, either because it constitutes a fundamental part of them or because it results in the whole work, we will reflect on the different possible strategies to make them accessible to the viewer, allowing a complete experience of the work.
\end{abstract}

Keywords: paratext; paratextuality; paratranslation; translation; contemporary art; Madrid International Contemporary Art Fair. 


\section{RÉSUMÉ}

Partant du concept de « paratexte » de Genette (1987), sur la base duquel la théorie de la « paratraduction » de Yuste (2015) est développée, nous nous demandons ce qui se passe en ce qui concerne l'expérience du spectateur, quand une oeuvre présente des éléments textuels dans une langue différente de la sienne. Nous identifions donc les éléments verbaux présents dans les oeuvres exposées dans les salons $\mathrm{d}$ 'art en accordant une attention particulière à la Foire Internationale de l'Art Contemporain de Madrid (ARCO). Etant donné que peu d'études prennent en compte l'aspect linguistique du spectateur, nous analysons la pertinence de la présence de la figure du traducteur dans des événements de ce type. A partir d'une sélection d'oeuvres dans lesquelles le texte fait partie de l'expérience visuelle, soit parce qu'il en constitue une partie fon $\neg$ damentale, soit parce qu'il découle de l'ensemble de l'oeuvre, nous envisageons différentes stratégies pour les rendre accessibles au spectateur, lui permettant d'avoir une expérience complète de l'oeuvre.

Mots clés : paratextualité ; paratextualité ; paratraduction ; traduction ; art contemporain ; Foire Internationale d'Art Contemporain de Madrid. 


\section{Introducción}

"Una imagen vale más que mil palabras". Quizá hayamos escuchado esta máxima en numerosas ocasiones, sin plantearnos hasta qué punto es cierta. La invasión gráfica de nuestro día a día no hace sino corroborar esta afirmación. Pero ¿̇comprendemos verdaderamente la información que llega a través de nuestra retina? En la actualidad, la idea de la aldea global está tan arraigada, que a menudo olvidamos que, por fortuna, seguimos siendo individuos con un entorno único y unas circunstancias concretas, que pueden ser o no similares a otros entornos y contextos.

No vamos a considerar el concepto de imagen en su sentido más abstracto, esto es, el resultado que nosotros mismos obtenemos de la percepción de nuestro entorno, en tanto que se convierte en representación visual al ser captado por nuestra retina. En este artículo, por el contrario, abordamos manifestaciones visuales más concretas, enmarcadas en un contexto determinado. Si partimos de la base de que para interpretar el mensaje inherente a una imagen no necesitamos palabras, pues esta se expresa por sí misma, posiblemente no estemos tomando en cuenta quién creó esa imagen, con qué fin o en qué contexto; y, por supuesto, tampoco contemplamos la posibilidad de una interpretación errónea por parte del receptor de dicha imagen.

Si, para que una obra literaria de un autor extranjero pueda llegar al grueso de un mercado concreto, una de las estrategias principales pasa por la traducción de esa obra a la lengua mayoritaria o principal de dicho público objetivo, y las campañas publicitarias que mantienen algún idioma extranjero han calibrado milimétricamente el factor exótico o ininteligible, ¿qué lleva a un comisario a plantearse la exposición de una obra de un autor extranjero que incorpora texto en una lengua ajena al público mayoritario, sin incluir ningún tipo de soporte lingüístico para su comprensión? No se trata de que cada obra venga acompañada de una disertación sobre su interpretación, pues alteraríamos igualmente la experiencia artística, sino de hacer accesible la totalidad de la experiencia artística al espectador.
El objetivo general de este artículo es el análisis de los elementos textuales presentes en una serie de obras de arte contemporáneo expuestas en la Feria de Arte Contemporáneo de Madrid (ARCO) y del soporte lingüístico ofrecido al espectador a este respecto, así como aportar propuestas de traducción adecuadas a este contexto concreto.

En cuanto a los objetivos específicos, se establecen los siguientes:

1. Revisar la bibliografia especializada, para establecer un marco teórico referencial sobre las nociones de paratexto y de paratraducción.

2. Establecer la pertinencia de la figura del traductor en el marco específico de Feria de Arte Contemporáneo de Madrid (ARCO), en su edición de 2013, como soporte a la localización. ${ }^{1}$

3. Proponer estrategias para la traducción y la localización de dichos elementos textuales, haciéndolos accesibles al espectador, permitiéndole tener una experiencia completa de la obra.

\section{Método}

Si bien se ha escrito mucho sobre la interacción entre texto e imagen en las obras plásticas, los análisis se han centrado en la interacción en sí (Litz, 2002; Opilowski, 2013; Stein, 2008; Ströbel, 2013) o en la representación textual (Sturge, 2014) y cultural (Hooper-Greenhill, 2000; Karp y Lavine, 1991), obviando la posible barrera lingüística entre el autor del mensaje y el receptor. Estos análisis, por lo tanto, no se han llevado a cabo desde una perspectiva traductológica: el traductor se ha ocupado de la traducción de los títulos de las obras de arte (Rodríguez, 2009; Serrell, 2015) o del soporte documental que acompaña a las exposiciones (Ortega y Martínez, 2006; Ravelli, 2006); incluso, en los análisis funcionales de traducción museística elaborados por Liao (2018), se proponen numerosos aspectos que

1 Con ello nos referimos a la localización en el sentido que proponía la Asociación de Estándares del Sector de la Localización (LISA), es decir, a adaptar un producto para el mercado al que se pretende llegar. 
abarcan gran parte de la complejidad y la multimodalidad de una exposición artística, pero no hay un análisis concreto de los elementos textuales presentes en las obras en sí. Por todo ello, nuestra primera tarea es revisar la bibliografía específica, para poder establecer un marco teórico que englobe los objetivos planteados en el presente artículo.

Como ya hemos anticipado, nos centramos en obras plásticas de arte contemporáneo en las que el texto forma parte de la experiencia visual. Para ello, observamos la estrategia expositiva empleada con las obras de arte cuyos elementos textuales constituyen una parte fundamental de las mismas o bien resultan en la totalidad de la obra. Tomamos como punto de referencia la Feria de Arte Contemporáneo ARCO 2013, celebrada en Madrid del 14 al 17 de febrero de 2013, puesto que se trata del evento de arte contemporáneo con proyección internacional más importante en España, donde comprobamos in situ la ausencia de estrategias de acercamiento lingüístico empleadas por los expositores en el caso de trece obras concretas.

La selección de dichas obras obedece a dos criterios fundamentales:

1. La lengua usada, seleccionando aquellas en las que la lengua elegida por el artista haya sido el alemán, el español, el francés, el inglés, el italiano o el portugués. Se han excluido de este análisis obras cuyo texto se exprese exclusivamente en lenguas con alfabeto no occidental.

2. El porcentaje de elementos verbales presentes en la obra es mayor respecto de los no verbales.

Además de los ejemplos seleccionados de la exposición en sí, comprobamos si estas obras se han incluido en el catálogo oficial de la muestra y qué información se incluye sobre las mismas en este soporte documental.

\section{Marco teórico}

En este apartado abordamos la revisión de la bibliografía especializada, a fin de poder establecer los parámetros referenciales sobre los conceptos de paratexto y de paratraducción.

\section{El concepto de paratraducción}

Yuste(2015) señala que el término "paratraducción” se creó en el seno del Grupo de Investigación Traducción y Paratraducción (T\&P) de la Universidad de Vigo, procedente del concepto de paratexto de Gérard Genette, quien abarcaba, en dicho concepto, las formas discursivas, icónicas, verbo-icónicas o materiales que acompañan al texto. Ese paratexto - que, en definitiva, no es el elemento textual y, por lo tanto, había quedado excluido de las prácticas traductológicas - entra de lleno en escena para el traductor, en el momento en que se concibe que no solo forma parte del mensaje que transmite el texto, sino que, en no pocas ocasiones, es un elemento de trascendencia fundamental: "si no puede existir un texto sin paratexto (Genette, 1987, pp. 9-10), tampoco puede existir traducción sin su correspondiente paratraducción. La paratraducción introduce y presenta la traducción como tal en la lengua y cultura de llegada” (Yuste, 2005, p. 76).

Yuste insiste en que el paratexto es más que el contexto o la situación comunicativa de las teorías traductológicas funcionalistas. Así, Yuste propone la siguiente traducción para la afirmación de Genette (1987): "Y si el texto sin paratexto es a veces como un elefante sin cornaca, potencia ineficaz, el paratexto sin su texto es como un cornaca sin elefante, necia ostentación" (p. 413, traducido en Yuste, 2015, p. 327).

Sin embargo, las teorías funcionalistas, con autores como Nord (2012) a la cabeza, han expresado en repetidas ocasiones su desacuerdo con este planteamiento, al afirmar que no era más que renombrar algo previamente existente en el ámbito traductológico: "se trata de darle un nombre bonito a la vieja rueda de la traducción” (p. 406).

Esto ha derivado en una avivada dialéctica entre ambas corrientes. 
Más allá del estado académico de ambas posturas, lo cierto es que el concepto de paratexto ha tenido un hondo calado entre no pocos autores actuales, demostrando la vigencia de la cuestión.

En junio de 2018, Baker organizaba y presentaba una jornada sobre traducción llamada Paratextual Framing: Theory and Methodology. En ella, la propia autora ofrecía una ponencia en la que pretendía ir más allá del concepto tradicional de Genette. En esta aportación, plantea la traducción como objeto del marco paratextual, siendo, al mismo tiempo, el propio marco paratextual. Otro aporte fundamental que revisa el concepto desde su aparición es la obra de Batchelor (2018), donde la autora analiza el desarrollo del concepto de Genette en varias disciplinas, prestando especial atención al impacto de este en los estudios sobre traducción. Esta obra resulta muy ilustrativa, pues, si bien queda claro la amplia repercusión del concepto de paratexto y, por tanto, la necesidad de tenerlo en cuenta en la traducción, no parece estar de acuerdo con el término "paratraducción":

Whilst perhaps helpful as a means of calling attention to the involvement of multiple agents in the process of publishing translations and the complexity of the translation process, the need for a new term and concept to emphasise these aspects is not at all clear. Over the last thirty or more years in translation studies in many regional and national traditions considerable attention has been paid to the cultural and ideological factors that play into the translation process, without adoption of a new term in place of translation (Batchelor, 2018, p. 152).

La autora señala que, a lo largo de los últimos años, la investigación en el ámbito de la traducción ha estado marcada por la ampliación del concepto de traducción en sí, de forma que la idea inicial, construida desde una óptica meramente lingüística y centrada en el carácter textual, ha avanzado hacia una concepción más amplia, en la que tienen cabida la ideología, el contexto histórico, las dinámicas culturales, las estructuras e interacciones sociales, y también la interacción entre los elementos verbales y no verbales (Batchelor, 2018, p. 153). De este modo, prefiere hablar de "traducir el paratexto", en lugar de acoger el concepto de paratraducción.
Another disadvantage of the term paratranslation is that it subsumes a range of different creative and commercial activities under a term that contains the word translation and thus risks implying that the objects under study involve some kind of interlingual transfer. [...] "Since, in many cases, paratexts are not translated per se but reimagined or completely transformed" (Watts 2005,161 ), adopting terminology that allows for as much as openness as possible with regard to the type of activities that are involved is clearly desirable (Batchelor, 2018, p. 152).

A tenor de lo hasta acá enunciado, aunque el concepto de paratexto es ampliamente aceptado por la comunidad, no parece suceder lo mismo con el término "paratraducción"; la argumentación para ello, expuesta por Batchelor (2018), nos parece ampliamente justificada.

\section{La importancia de la interacción semiótica}

Si bien no nos detenemos, en este artículo, en la definición del concepto de semiótica, conviene recordar que "La carta Constitucional de la International Association for Semiotic Studies/Association Internationale de Sémiotique, de 1969, mantiene que Semiótica y semiología son términos sinónimos" (Bobes, 1989, p. 14). A pesar de que varios autores propongan terminologías específicas para cada uno de los conceptos, lo cierto es que ambos se refieren a la ciencia de los signos en sentido general (Yuste, 1998).

El sentido de los signos literarios se inicia en su soporte lingüístico, se transforma o se matiza con las relaciones en que se sitúan en la obra y con otros textos y realidades extratextuales; se establece a través de relaciones horizontales con otros signos literarios del discurso, o mediante relaciones verticales con unidades de otros niveles. El sentido único de una lectura concreta se forma al relacionar todo lo que dinámicamente es capaz de interpretar el lector (Bobes, 1989, p. 95).

Es esta alusión a la capacidad e interpretación a la que alude Bobes, la que hace decir a Yuste (1998) que:

El sentido de cualquier texto está vinculado a su situación de uso, a las circunstancias en que se produce el proceso de expresión, de comunicación, de interpretación de los signos que el autor-emisor desea transmitir. Y dicha transmisión se realiza por un autor-emisor determinado, en 
un tiempo determinado, en un espacio determinado, en una cultura determinada y para un lector-receptor determinado (p. 519).

Así, este autor concluye que: "Las posibilidades de significación de un signo dependen enormemente pues de la competencia de los sujetos del proceso semiótico" (Yuste, 1998, p. 519).

Además (o por ello),

El traductor/intérprete debe saber reconocer que el significado no es una entidad estable independiente del momento y del lugar, sino todo lo contrario. No puede olvidar que el carácter de la imaginación empleada, el tipo de imaginario específico presente en cada texto, varía según los ambientes sociales donde se ha creado, las épocas históricas, los movimientos estéticos, las sensibilidades de los autores. Por lo tanto, el traductor/intérprete debe centrarse en la observación minuciosa del poder imaginativo en una situación concreta determinada - la del texto literario - en el seno del contexto social, histórico, antropológico [...] en una palabra, en el seno humano, de donde surge (Yuste, 2001, p. 811).

Esto nos lleva directamente a la retórica de las imágenes de Barthès, idea recogida en su ensayo básico y fundamental (Image music text) (1977) en lo que a interacción semiótica se refiere. En dicho ensayo, este autor analiza el contexto de la imagen; para ello, estudia un anuncio publicitario y se plantea cómo la imagen obtiene su significado y hasta dónde llega la interpretación. Barthès (1977) establece tres categorías para el significado de una imagen: el mensaje lingüístico, un mensaje icónico codificado y un mensaje icónico no codificado. Así, el mensaje lingüistico se encuentra en los pies de foto, en las etiquetas, en los artículos de prensa que acompañan a las imágenes en sí, en los diálogos en las películas o en los bocadillos de las tiras cómicas. Este mensaje puede ser connotativo o denotativo. El mensaje icónico codificado es la propia imagen. Para asimilar este mensaje, uno necesita conocer el trasfondo cultural que origina la imagen.

El tercer mensaje, el mensaje icónico no codificado, está constituido por el objeto y su escena, la relación entre el código significado y la representación analógica: "all images are polysemous; they imply, underlying their signifiers, a 'floating chain' of signifieds, the reader able to choose some and ignore others" (Barthès, 1977, p. 156).

En toda su polisemia, la imagen forma un tándem indisoluble con el texto que la acompaña y es este nexo el que el traductor no debe obviar. En este binomio, no obstante, la imagen no siempre ha tenido el reconocimiento debido; Holländer (1978) considera que con frecuencia el mensaje escrito o hablado prevalece sobre el icónico y esto puede deberse a la inexistencia de un marco teórico desarrollado sobre la imagen como lenguaje (Kress y Van Leeuwen, 1996, pp. 20-21). Sin embargo,

It has become clear that the two are inseparable because they are constitutionally part of one another. Starting from the word-end, so to speak, we found that the image cannot be extirpated from language because language is by definition a sort of image and therefore depends on the image if it is to exercise its (conventional) function properly (Heusser, 1993, p. 17).

Honegger (2002, p. 17) recuerda que, en el eterno debate sobre la interrelación entre texto e imagen, suele emplearse de forma recurrente una cita de Goethe, en la que el autor establece la correlación entre el mensaje escrito y la imagen, y con la que nosotros queremos concluir este apartado:

La palabra y la imagen son correlaciones que se buscan constantemente, como nosotros vamos tomando conciencia suficiente de los trópicos y las parábolas. Así, desde tiempos inmemoriales, lo que viene dicho o cantado al oído debiera también llegar a la vista (Goethe, citado en Gottfried, 1991, p. 414; la traducción es nuestra).

\section{Resultados: la traducción de obras de arte contemporáneo}

Nothing is an artwork without an interpretation which
constitutes it as such
Danto (1981, p. 135)

Junto con un conocimiento más o menos versado sobre el lenguaje visual, al espectador de obras de arte contemporáneo se le exige el dominio de idiomas, incluso varios, pues en no pocas obras se emplea 
texto como parte integrante de la experiencia visual. Quizás otrora el idioma imperante en el arte fuera el francés, como nos puede hacer pensar la serie de cuadros La perfidia de las imágenes (La trahison des images) (1928-1929) de René Magritte, en donde encontramos la famosa leyenda Ceci n'est pas une pipe, pero en la actualidad el inglés es, sin duda, la lengua imperante, pues es usado por artistas angloparlantes y no angloparlantes. No obstante, pensar que solo se emplea el inglés o el francés reducirá considerablemente las experiencias artísticas. Un paseo por cualquier galería de arte con proyección internacional nos sacará de este error y podremos comprobar, no sin cierto desasosiego, que no entendemos literalmente la obra que tenemos delante.

Como ya hemos señalado antes, nos centramos en este artículo en las obras expuestas en la Feria de Arte Contemporáneo (ARCO), que se celebra anualmente en el recinto de IfEMA (Madrid, España), el

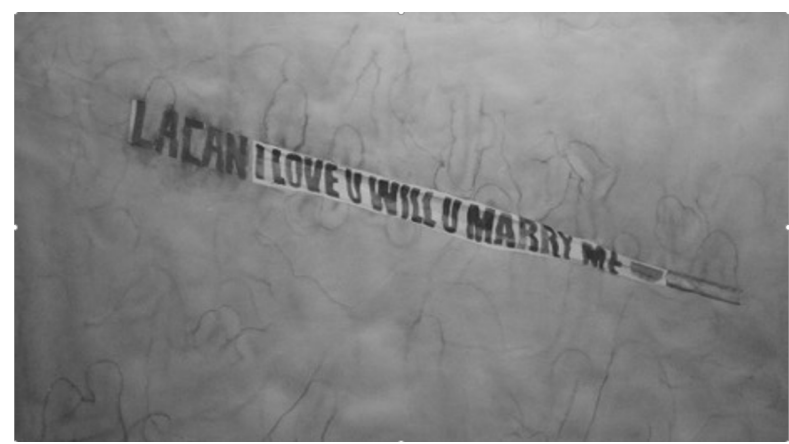

Figura 1 Lacan I love U (Pérez Agirregoikoa, 2011)

Fuente: Fotografía de Rocío Márquez Garrido. evento español de este tipo con mayor proyección internacional. Según la propia página de la feria:

la obra seleccionada abarca las vanguardias históricas, los clásicos contemporáneos y el arte actual. Las galerías incluidas en el Programa General y las que forman parte de los programas comisariados exponen pintura, escultura, instalaciones, fotografía, vídeo, new media, dibujo y grabado (IFEMA, 2015, párr. 1).

Para este artículo, se han seleccionado trece obras que, por sus características concretas, resultaban interesantes ejemplos para ilustrar las estrategias o, mejor dicho, la ausencia de estrategias de localización de los contenidos expuestos.

\section{Las obras expuestas in situ en ARCO 2013}

Comenzamos este apartado con el artista español Juan Pérez Agirregoikoa (San Sebastián, 1963), que, como vemos en las imágenes, ha empleado la lengua inglesa como recurso para incluir el mensaje de su obra. En ambos casos, además del texto

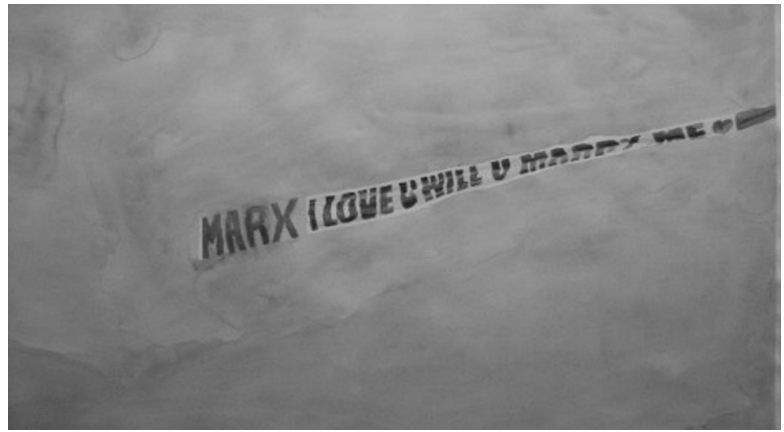

Figura 2 Marx I love U (Pérez Agirregoikoa, 2011)

Fuente: Fotografía de Rocío Márquez Garrido.

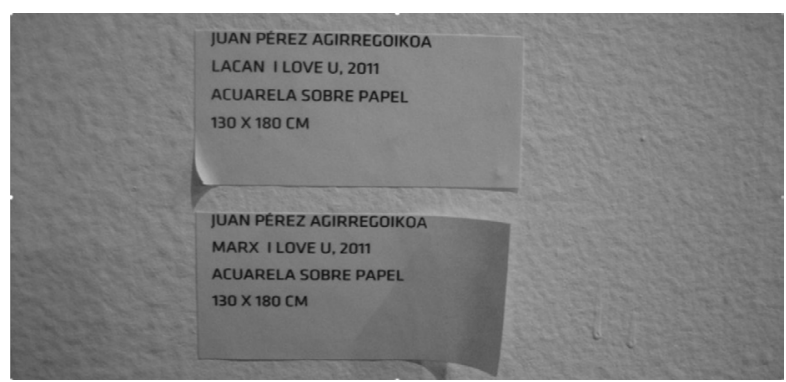

Figura 3 Cartelas identificativas de las obras de las Figuras 1 y 2 en ARCO 2013

Fuente: Fotografía de Rocío Márquez Garrido. 
incluido en la obra que conforma también el título, puede leerse "MARRY ME", seguido de un corazón. El entorno de la obra no muestra información o explicación alguna sobre el texto que constituye el eje fundamental de ambas obras. Como se aprecia en las Figuras 1 a 3, el soporte lingüístico brilla por su ausencia.

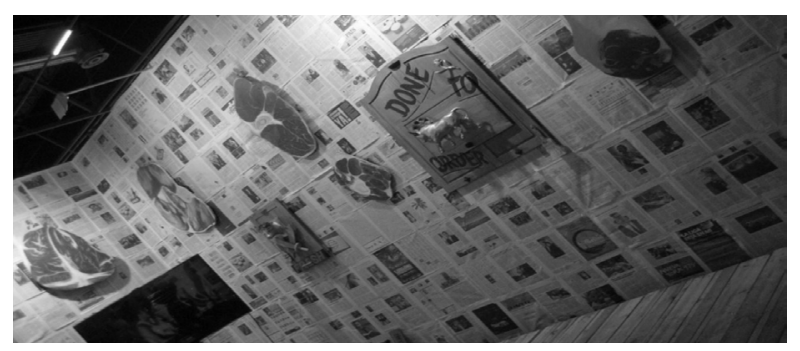

$a$

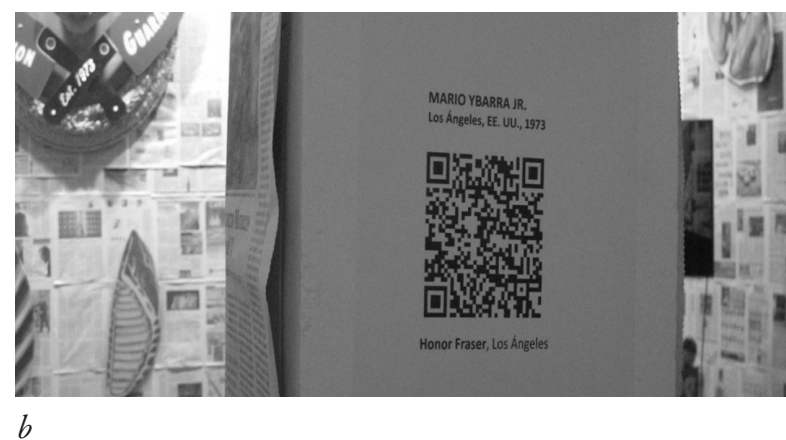

Figura 4 Instalación ...like a cow visiting a butcher shop... (YbarraJr., 2013).a. Vista parcial delainstalación; b. Cartela identificativa.

Fuente: Fotografía de Rocío Márquez Garrido.

El segundo caso estudiado (véase Figura 4) viene de la mano del artista estadounidense de origen mexicano Mario Ybarra Jr. (Los Ángeles, 1973) y su instalación ...like a cow visiting a butcher shop... En ella se combina un fondo de innumerables papeles de periódico, con esculturas y cartelas de diversos tamaños, además de varias pantallas, en las que se reproducía un vídeo en lengua inglesa de forma ininterrumpida.

En este caso, la galería proponía un recurso interactivo en forma de código $\mathrm{QR}$ para ofrecer al espectador más información. Esta, sin embargo, consistía en datos sobre el artista y su obra, pero en ningún momento se ofrecía un soporte lingüístico para ninguno de los elementos textuales que aparecen en la obra.

Resulta más que curioso esta ausencia de soporte lingüístico, ya que el concepto base en el que se apoya la instalación, según el propio artista, es hacer una crítica al mundo del arte, que muestra y vende las obras como si fueran mercancías, como la carne en una carnicería. Más curioso aún es que la galería (Honor Fraser), en cuyo espacio expone el artista, declare que ellos comparten la crítica del artista, si bien la limitan al ámbito angloparlante, al no proporcionar la información en otras lenguas:

Arco first-timer Honor Fraser's entire booth was turned into a kind of meat shop, with flat painted sculptures resembling pieces of meat by Mario Ybarra Jr. laid out in a storefront display. Whether chop, loin, or leg, the prices ranged between $\$ 5,000-18,000$, with the entire installation up for grabs for $\$ 70,000$. The idea behind the installation in the LA-based booth is
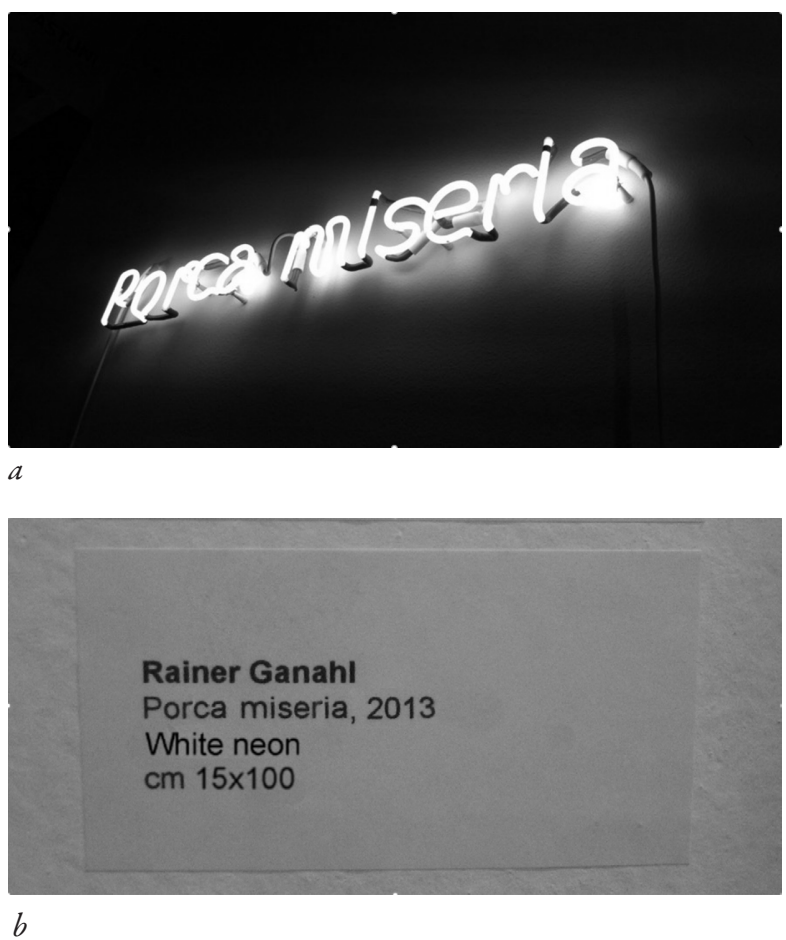

Figura 5 a. Porca miseria (Ganahl, 2013); b. Cartela identificativa de la obra.

Fuente: Fotografía de Rocío Márquez Garrido. 
the critique of art being dealt with as a commodity at art fairs, like meat in a butcher's. Undoubtedly it's the artist's idea, but according to the gallery, they share the critique of the artist (Ulrichs, 2013, p. 5).

Por otro lado, la obra seleccionada de Rainer Ganahl, artista austríaco afincado en Nueva York (Bludenz, Austria, 1961), no es una obra plástica con texto incorporado, sino que el texto en sí conforma la obra plástica (véase Figura 5).

Una vez más, no encontramos más información que el nombre del autor de la obra, la técnica empleada y sus dimensiones. Toda la obra de este autor gira en torno a cuestiones sobre la producción del saber y a las políticas educativas, esto es, qué enseñar, qué aprender, qué leer, sobre qué discutir y con quién (Galleria Enrico Astuni, 2018, párr. 3). Estos interrogantes se plantean con un fuerte espíritu crítico que, sin embargo, no vemos soportados por ningún elemento de traducción que haga posible que el espectador sin conocimientos de italiano entienda la afirmación incluida en la obra. Por tanto, la intención de interlocución o, al menos, de incitar a la reflexión que propone el artista, queda diluida en la apreciación meramente estética de las formas tipográficas y del color de la luz del neón empleado.

La imagen de la Figura 6a es una obra fotográfica que se titula $O \dot{u}$ allons nous?, al igual que el texto que

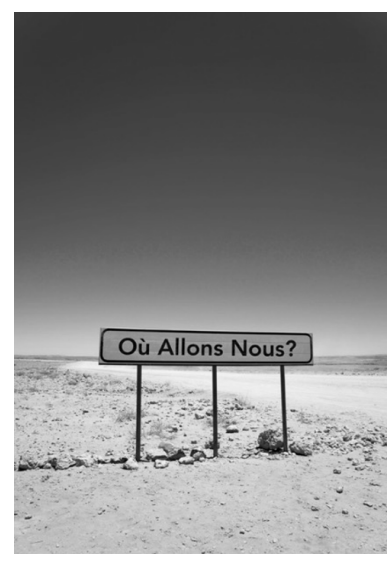

$a$

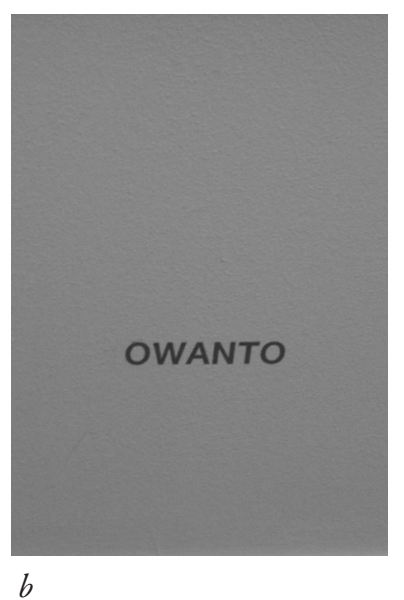

Figura 6 a. Ou allons nous? (Owanto, 2013); $b$. Inscripción identificativa de la obra. incluye la propia imagen. La Figura 6b, sin embargo, no se corresponde con ninguna otra obra, sino con el nombre de la autora de la obra fotográfica anterior, situado en la parte inferior derecha de la pared que la exhibía.

La artista francesa de origen gabonés Owanto (París, 1953), autora de la obra, suele emplear símbolos reconocidos universalmente (como la señal de tráfico), que facilitan la interpretación de su obra por un público de origen heterogéneo. En este caso, sin embargo, el símbolo enmarca un código lingüístico no tan universal, como es la lengua francesa. Este hecho no parece tener importancia para los expositores, a la luz de la ausencia de estrategias traductológicas que hagan accesible el contenido completo de la obra en cuestión.
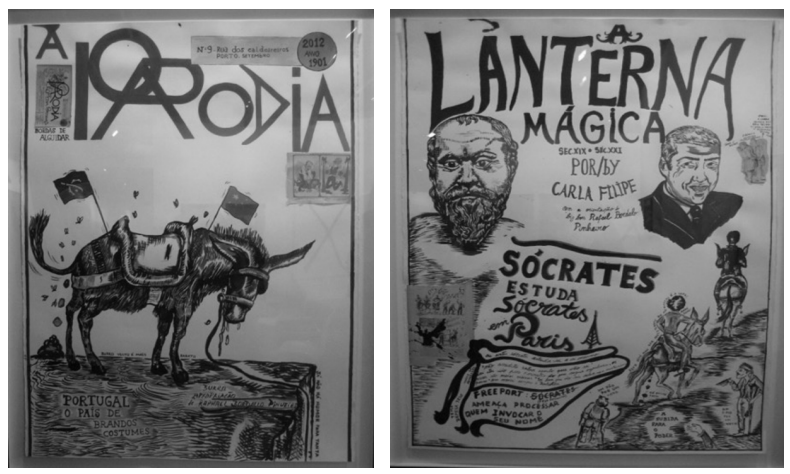

$a$

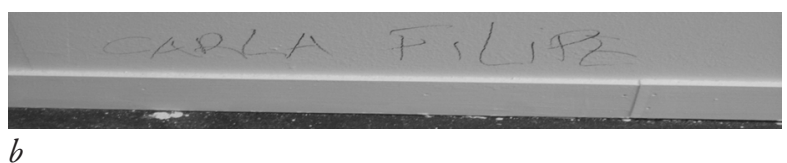

Figura 7 a. Obra de Carla Filipe, expuesta en Arco 2013; b. Inscripción identificativa de la obra.

Fuente: Fotografía de Rocío Márquez Garrido.

El caso de la artista Carla Filipe (Aveiro, 1973), autora de las obras correspondientes a la Figura 7, es igualmente llamativo. Como en el resto de los casos, no aparece soporte lingüístico de ningún tipo y, como ocurría en el caso anterior, solo se incluye el nombre de la autora, sin más información sobre los títulos o ficha técnica alguna. Esta vez, el nombre ni siquiera

Fuente: Fotografía de Rocío Márquez Garrido. 
se incluía en una cartela, sino que estaba escrito a lápiz en la misma pared que mostraba las obras.

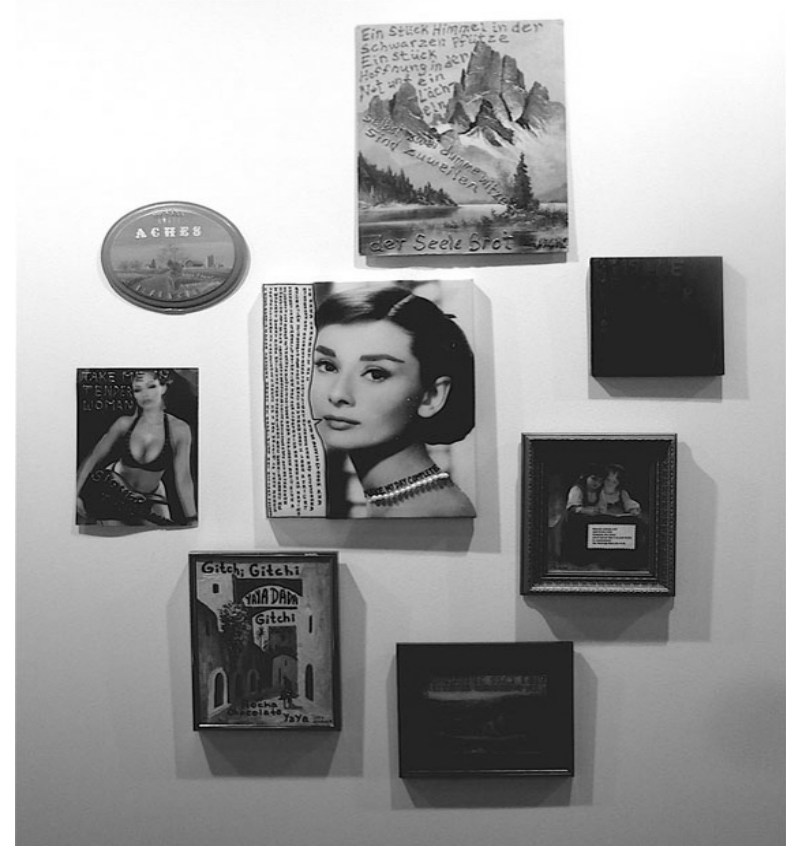

198

Figura 8 Montaje sin título (Kikauka, 2013)

Fuente: Fotografía de Rocío Márquez Garrido

La autora crea obras que parten de la cultura popular, con tintes activistas y, en cualquier caso, siempre invitando a la reflexión del espectador (32. ${ }^{\text {a Bienal }}$ de São Paulo, 2016, párr. 1), si bien nuevamente esta

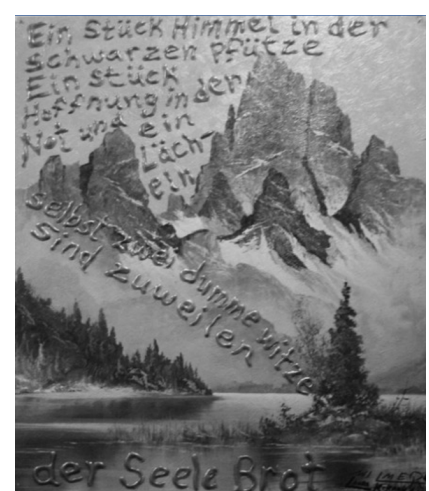

a

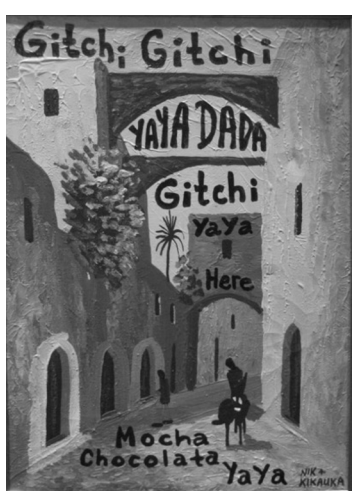

$b$
Figura 9 Detalles del montaje sin título de Kikauka (2013).a. Detalle con texto en alemán; $b$. Detalle con transcripción fonética de un segmento del estribillo de la canción Lady Mermalade.

Fuente: Fotografía de Rocío Márquez Garrido. invitación puede quedar sin receptor por una simple cuestión de desconocimiento lingüístico.

La obra mostrada en la Figura 8 pertenece a la artista canadiense Laura Kikauka (Ontario, 1963) y resulta muy interesante para nuestro análisis, por la mezcla de códigos presentes, que pasamos a ver de forma más detallada a continuación.

Mientras que la Figura 9a muestra un texto en alemán dispuesto sobre el paisaje de la pintura, la Figura $9 \mathrm{~b}$ presenta una especie de transcripción fonética de un segmento del estribillo de la canción Lady Marmalade, de 2002, parte de la banda sonora original de la película musical Moulin Ronge!, de 2001, dirigida por el australiano Baz Luhrmann.
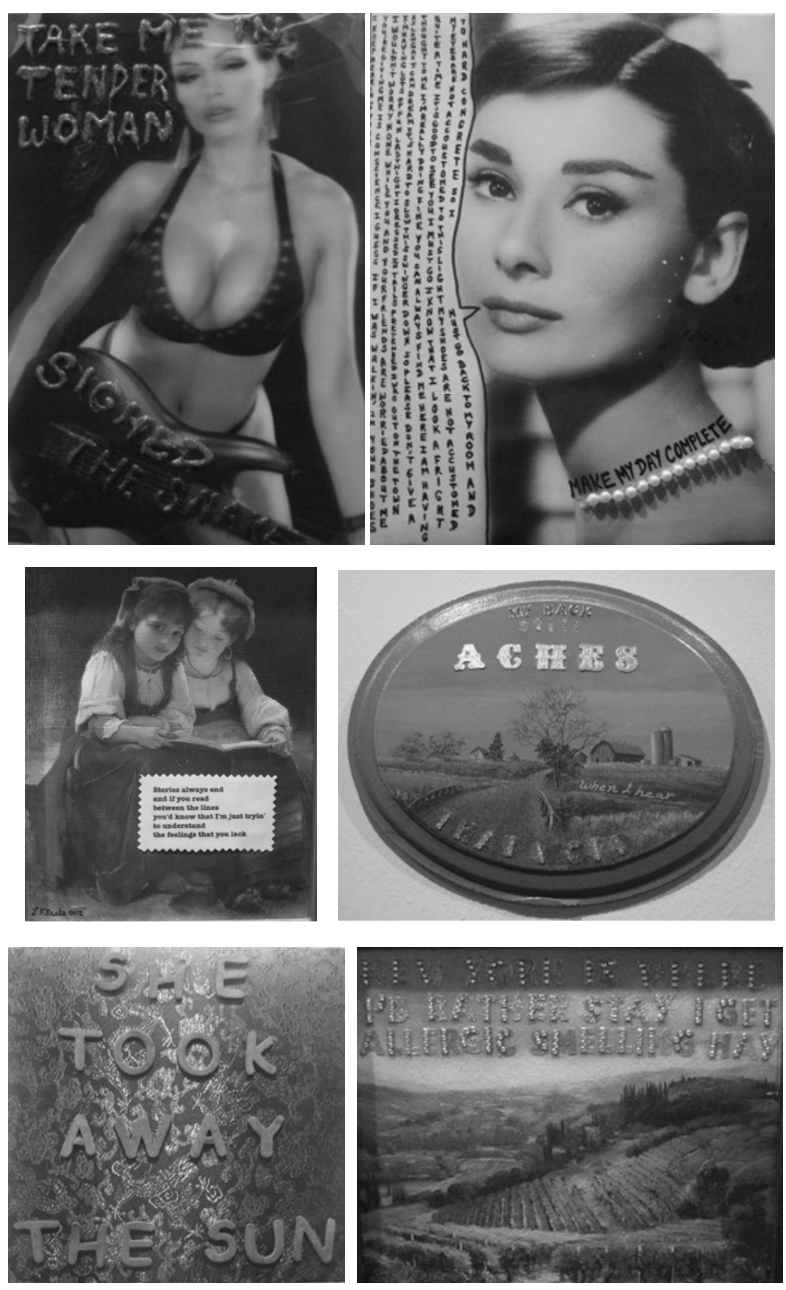

Figura 10 Detalles de las obras que componen el montaje sin título de Kikauka (2013)

Fuente: Fotografía de Rocío Márquez Garrido. 
En la Figura 10, la autora emplea texto en inglés para completar el mensaje de las imágenes. En ningún caso se ofrece soporte lingüístico, por lo que, para entender la totalidad de esta obra, el espectador debe tener amplios conocimientos de inglés y alemán, además de contar con un bagaje de la cultura pop suficiente como para poder identificar el texto de la Figura 9b; son estos unos requisitos bastante altos que pueden resultar un tanto excesivos para el espectador.

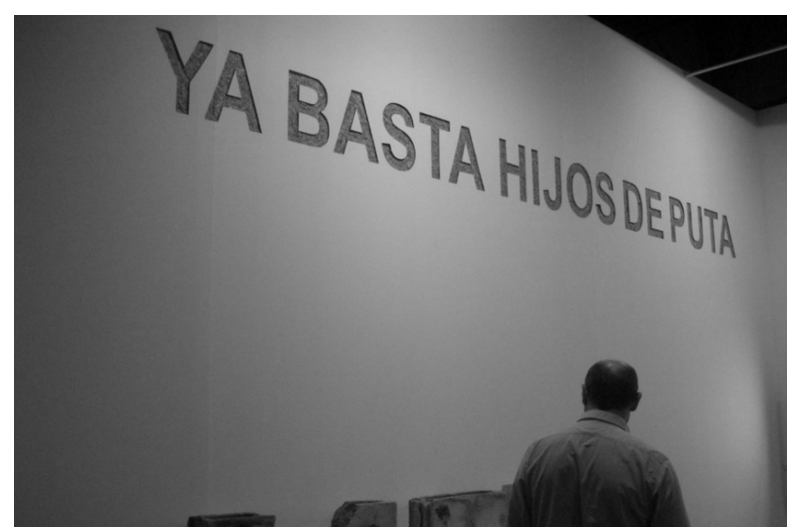

Figura 11 Ya basta hijos de puta (Margolles, 2013)

Fuente: Fotografía de Rocío Márquez Garrido.

La siguiente obra que analizamos (Figura 11) es de la artista mexicana Margolles (Sinaloa, 1963). La artista muestra "un trabajo siempre vinculado a la violencia de su país, así como a la experiencia directa de la fisicidad de lo corporal y la muerte" (Espejo, 2014, párr. 1). A pesar de que la obra es esencialmente una

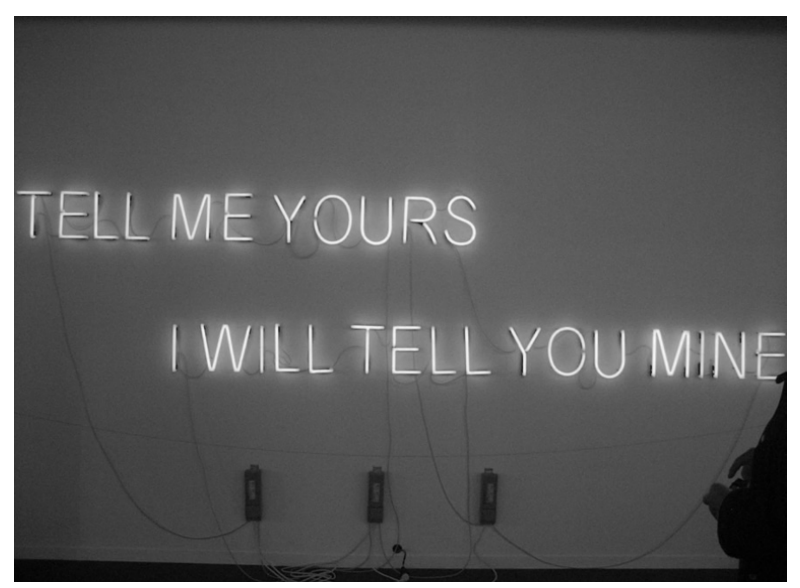

Figura 12 Tell me yours I will tell you mine (Duravcevic, 2012)

Fuente: Fotografía de Rocío Márquez Garrido disposición textual, no incluye ningún soporte lingüístico que pudiera facilitar o incluso permitir su comprensión.

La propuesta del artista montenegrino afincado en Nueva York Aleksandar Duravcevic es similar, en cuanto a técnica, a la obra de Ganahl (véase Figura 5a), si bien en este caso Duravcevic (1970) opta por el inglés para expresar el mensaje de su obra (véase Figura 12). Según la nota biográfica incluida en Totah, una de las galerías que expone su obra,

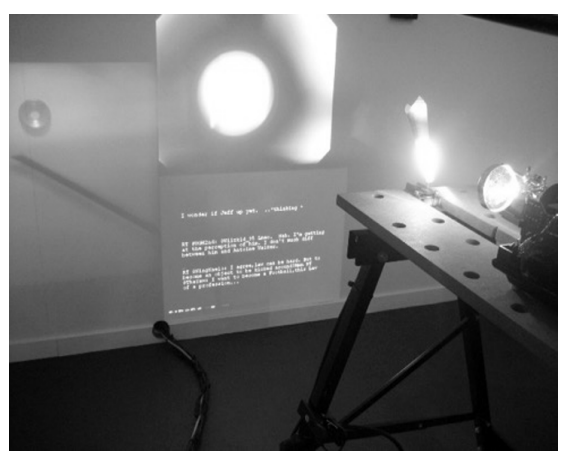

$a$
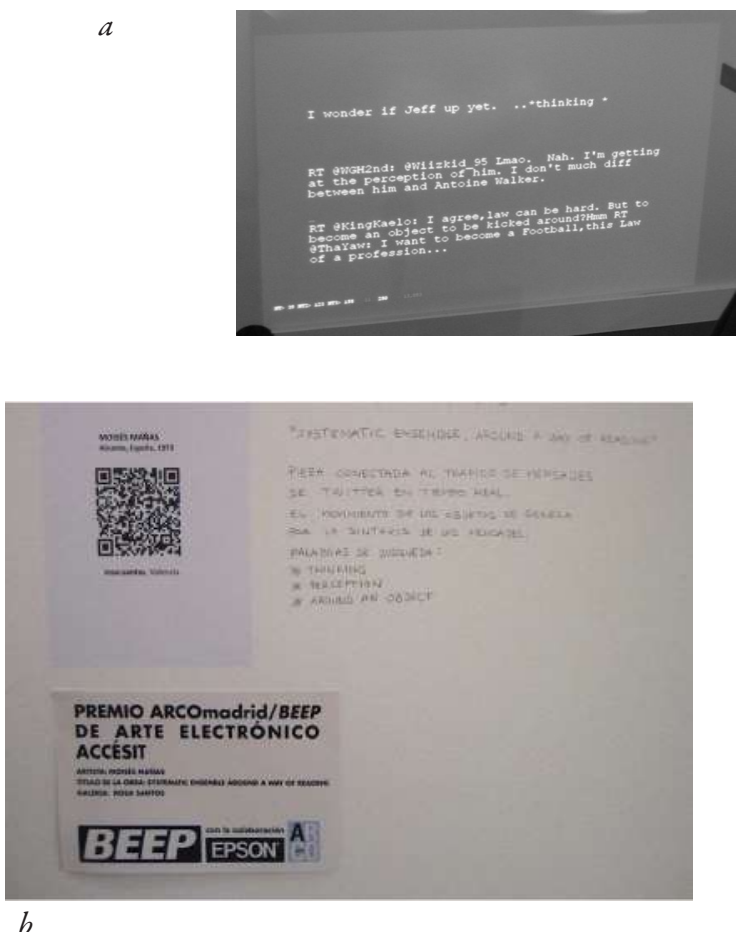

Figura 13 Instalación Systematic ensemble, around a way of reading (Mañas, 2013). $a$. Detalle; $b$. Cartela identificativa y explicativa de la instalación.

Fuente: Fotografía de Rocío Márquez Garrido. 
"Through these images he establishes a dialogue-a continuous investigation that stems from a personal need to open, to dissect, to catalog, to make a mark" (Totah, 2018, párr. 2). Esa necesidad comunicativa se ve considerablemente mermada cuando no se tiene en cuenta la barrera lingüística.

Otro ejemplo en este sentido es la instalación del español Moisés Mañas, que recibió el accésit al premio ARCOmadrid/BEEP de arte electrónico, por su obra Systematic ensemble, around a way of reading (véase Figura 13a).

Aquí los tres términos de búsqueda o hashtags seleccionados son también en inglés. Tal y como se explica en la Figura 13b, la pieza estaba conectada

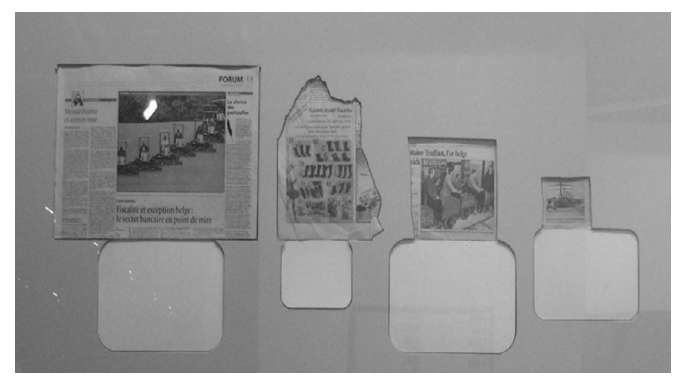

a
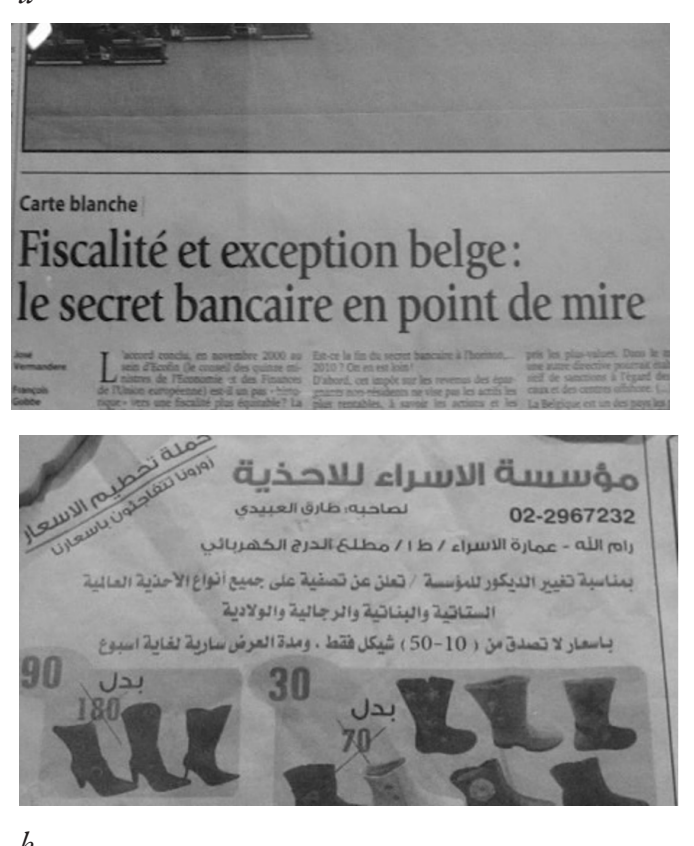

Figura 14 a. Systématique \# 1 (Tuerlinckx, 2012); b. Detalles.

Fuente: Fotografía de Rocío Márquez Garrido al tráfico de mensajes de Twitter en tiempo real y era la sintaxis de esos mensajes la que hacía que se movieran los objetos de la instalación.

A estas alturas del análisis, huelga decir que no hay planteamiento de soporte lingüístico alguno.

Por otra parte, en las obras seleccionadas de Joëlle Tuerlinckx se emplean recortes de periódico como elementos compositivos. Los textos de los recortes incluidos en la primera (véase Figura 14a, en más detalle en la Figura 14b) están escritos en francés y en árabe.

Los recortes de la obra mostrada en la Figura 15a (se pueden apreciar en mayor detalle en la Figura 15b), sin embargo, pertenecen a la prensa alemana y están

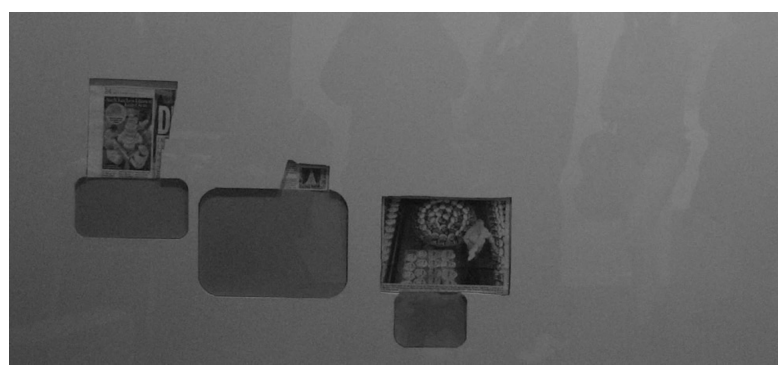

$a$

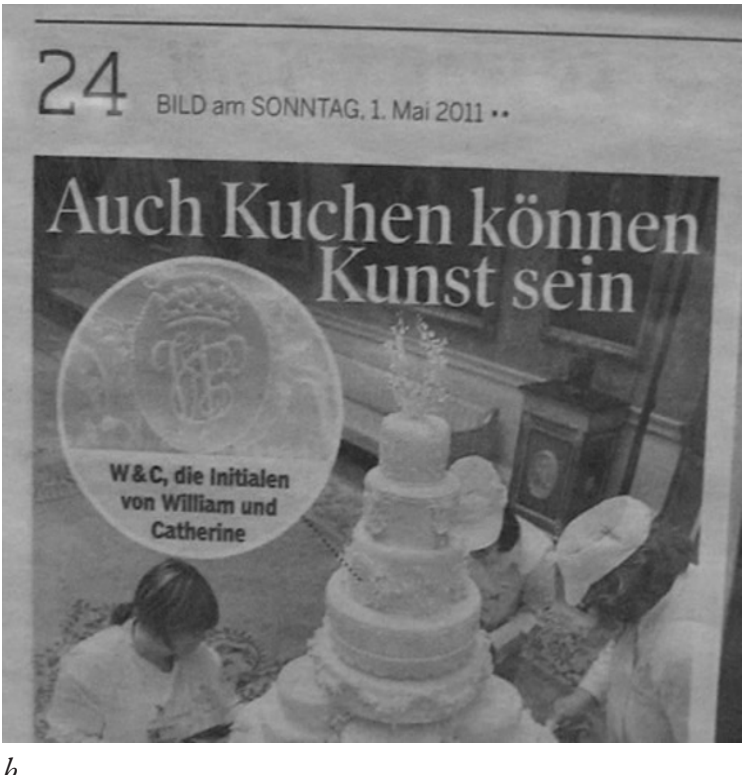

Figura 15 a. Systématique \#3 (Tuerlinckx, 2012); b. Detalle.

Fuente: Fotografía de Rocío Márquez Garrido 
escritos en alemán. Debemos tener en cuenta la siguiente consideración sobre la artista:

Tuerlinckx's art is based on a sustained and timeconsuming engagement with simple things; for three decades, she has gathered found items or articles of daily use that crossed her path and methodically collected them in a comprehensive archive. These objects have inspired her to reflect on what it means to be a human being — they are, to use the artist's term, elements of the real. Her work grows out of the observation, experimental application, and, as she calls it, transcription of these elements: a kind of (re)reading that seeks to strip them of their ostensible banality and comprehend and show them for what they truly are (Kunstmuseum Basel, 2017, párr. 2).

La intencionalidad que la artista proclama sobre deshacerse de la banalidad de los objetos y mostrar su verdadera esencia resulta complicada de

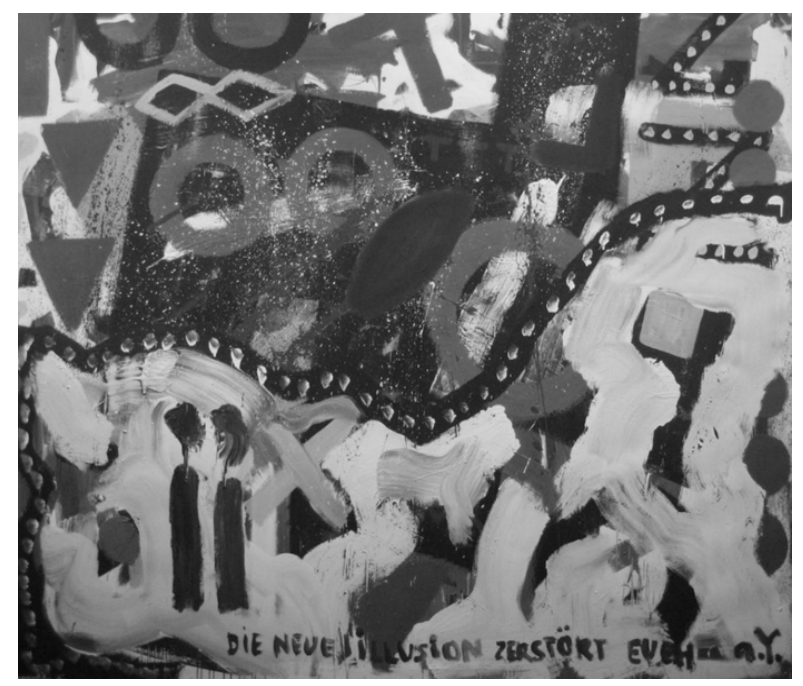

Figura 16 Die neue Illusion zerstört euch (Penck, 1983).

Fuente: Fotografía de Rocío Márquez Garrido.

entender si no somos capaces de comprender los textos incluidos en los recortes.

Por último, hemos decidido terminar el análisis con una de las obras pictográficas de A. R. Penck, donde el texto incluido en la imagen no parece desempeñar a priori un papel protagónico; no obstante, esto cambia cuando nos percatamos de que es el mismo texto que compone el título de la obra (Figura 16).
Es este un claro ejemplo de la simbiosis entre la imagen y el texto que mencionaba Heusser (1993) y que recogía Stein (2008) en su análisis de la interrelación entre texto e imagen en el arte contemporáneo, pues el texto no es que esté supeditado a la imagen, sino que ambos forman una única entidad.

Como hemos podido ver a lo largo de este recorrido, los elementos textuales no han tenido ninguna estrategia expositiva de acercamiento al espectador; más bien han sido tratados como otro elemento más del conjunto plástico, lo que reduce la experiencia artística del espectador al lenguaje icónico-visual, obviando el mensaje lingüístico incluido deliberadamente por el autor en la obra, y que es una parte fundamental del mensaje global de la misma.

$\mathrm{Ni}$ siquiera las cartelas, que, como ya habíamos mencionado, habían sido objeto de estudios traductológicos en el entorno museístico (Rodríguez, 2009; Serrell, 2015), han tenido un tratamiento lingüístico. La ausencia total de cubrir lo que calificamos como una necesidad del espectador, llama poderosamente la atención; vemos, por lo tanto, que las últimas tendencias en las prácticas museísticas no se aplican necesariamente a contextos expositivos temporales, como el caso que nos ocupa.

\section{Las referencias en el soporte documental oficial de ARCO 2013 de las obras seleccionadas}

Una vez comprobada la ausencia de estrategia in situ, podríamos pensar que quizás el catálogo de la exposición, uno de los dos soportes documentales principales a disposición del espectador, pueda contener más información. Debemos aclarar que la feria dispone de un catálogo oficial (IFEMA) ARComadrid, 2013a), con información general sobre ella, donde incluye la información esencial, en la que se detallan la distribución de los espacios, las galerías participantes y sus artistas, y un Libro de artistas (IFEMA/ARCOmadrid, 2013b), que abarca información de un artista destacado por cada galería participante. 
De los diez autores analizados en el apartado anterior, solo cuatro aparecen en dichos soportes documentales. Concretamente, en el Libro de artistas (IFEMA/ARCOmadrid, 2013b) están recogidos Juan Pérez Agirregoikoa, Mario Ybarra Jr., Carla Filipe y Moisés Mañas. Del resto de autores y sus obras solo tenemos la información que encontramos in situ, es decir, en las cartelas informativas (cuando las hay). No hallamos, por lo tanto, referencia alguna ni en el catálogo oficial (IFEMA/ARComadrid, 2013a) ni en el Libro de artistas (IFEMA/ARCOmadrid, 2013b) acerca de Ganahl, Owanto, Kikauka, Margolles, Duravcevic ni Tuerlinckx, pues ninguno de ellos se encuentra entre los artistas destacados de sus respectivas galerías.

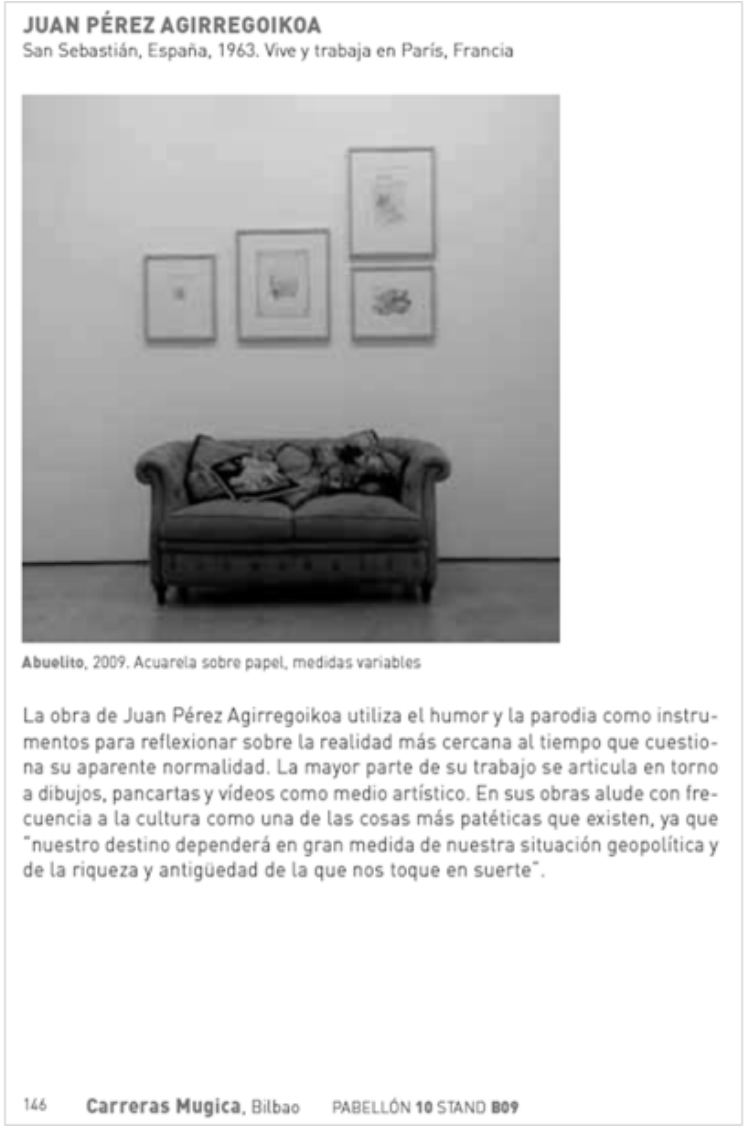

Figura 17 Presentación de Juan Pérez Agirregoikoa en el Libro de artistas

Fuente: IFEMA/ARCOMadrid (2013b, p. 146).
A continuación analizamos qué información adicional hay en los soportes documentales, en el caso de los cuatro artistas incluidos en ellos.

En primer lugar, para Pérez Agirregoikoa (Figuras 1 y 2), el Libro de artistas (véase Figura 17) muestra información sobre el artista y su obra, pero la imagen que acompaña esta información no se corresponde con la obra expuesta en ARCO 2013, por lo que no hallamos nada que nos ayude a interpretar la obra in situ.

El segundo ejemplo corre a cargo del estadounidense de origen mexicano Mario Ybarra Jr. (Figura 4) (véase Figura 18).

Nos parece muy interesante que el propio catálogo haga hincapié en el carácter comunicativo de la obra de este artista y no tenga en cuenta que, para que se

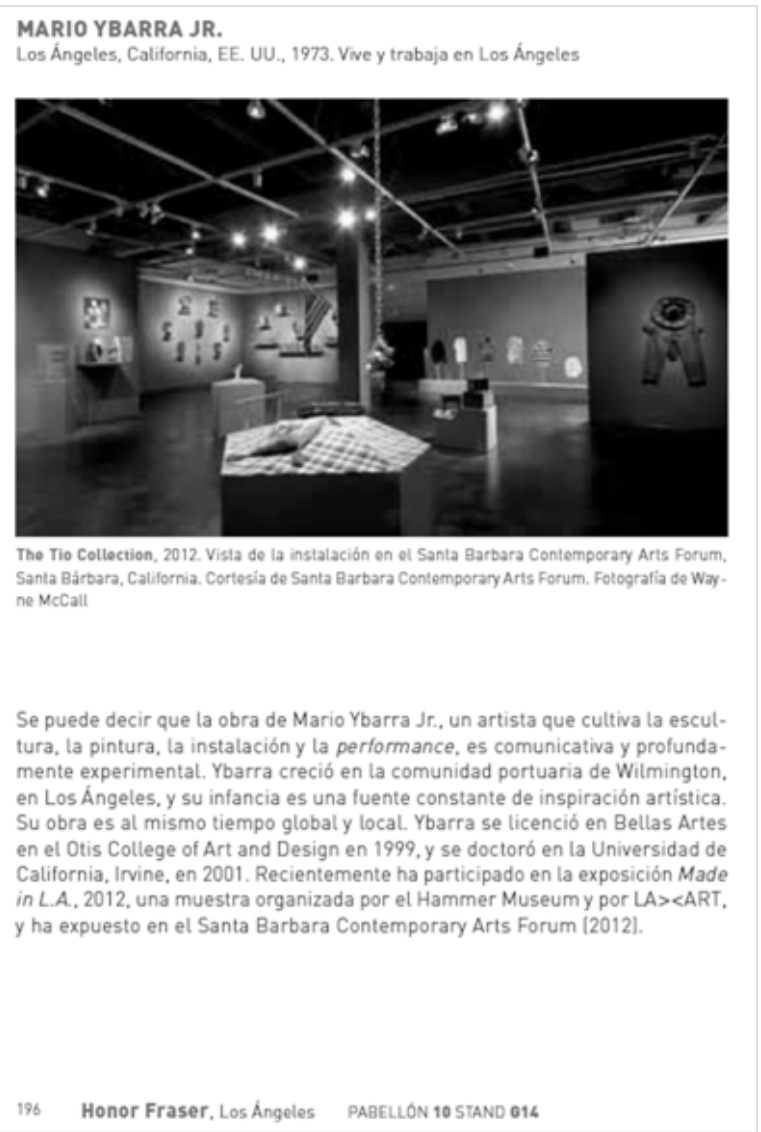

Figura 18 Presentación de Mario Ybarra Jr. en el Libro de artistas

Fuente: IFEMA/ARCOMadrid (2013b, p. 196). 


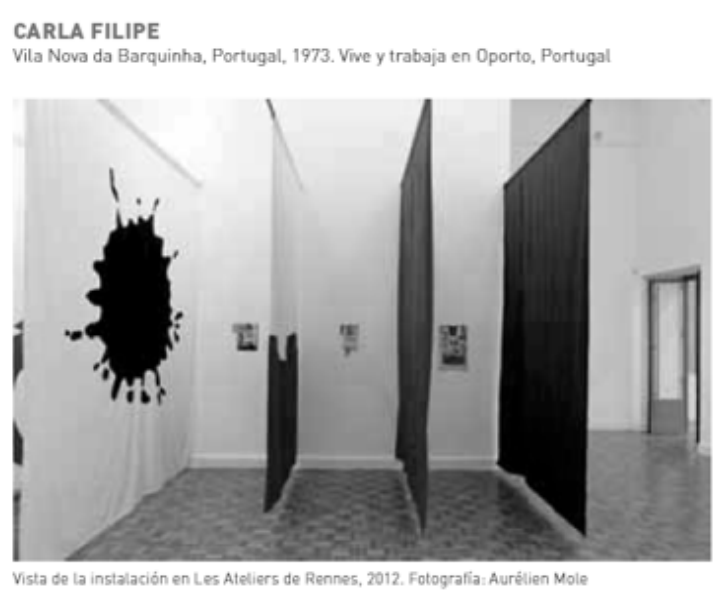

Carla Filipe es una de las artistas más singulares de la escena portuguesa actual. Su obra se sitúa en un ámbito en el que las fronteras entre la llamada "alta cultura" y la cultura popular se confunden inevitablemente. Tanto en las obras en las que revisa el pasado de su familia como en las que investiga los rasgos caracteristicos de ta potitica y ta sociedad de Portugal. Ia artista finge una falsa inocencia que realza la naturaleza tragicómica de sus propuestas. Filipe ha expuesto sus obras en la Bienal Manifesta 8 (comisariada por Tranzit.orgl, en la Bienal de Jafre Icomisariada por Carolina Graul, en Les Ateliers de Rennes (comisariada por Anne Bonnin], en CGAC Icomisariada por Miquel von Hafe Pérezl, en Kunsthalle Lissabon Icomisariada por Luis Silva y João Mourãol y en otros espacios. En 2013. inaugurará una exposición individual de su obra en el Museu Colecçăo Berardo [comisariada por Pedro Lapal.

Nuno Centeno, Oporto PaBELLÓN 10 STAND Do3

Figura 19 Presentación de Carla Filipe en el Libro de artistas

Fuente: IFEMA/ARCOMadrid (2013b, p. 77).

lleve a cabo dicha comunicación, el receptor tiene la tarea de decodificar el mensaje una vez le es entregado (Dainton y Zelley, 2004).

Como ya ocurría con el artista anterior, tampoco en este caso se hace referencia a la obra expuesta in situ, sino que se da información sobre el artista, sin ninguna referencia al soporte lingüístico.

Por otra parte, las obras de Filipe (Figura 7a) no venían acompañadas de cartelas identificativas, sino de su nombre escrito a lápiz de forma apresurada sobre la pared que mostraba su obra. No obstante, resulta ser la artista destacada de la galería que la exhibe y podemos encontrarla en el Libro de artistas (Figura 19). Como en los dos casos anteriores, la obra incluida en la publicación no coincide con la expuesta en la feria, por lo que, salvo la breve reseña sobre la artista y su obra, no tenemos más información.

\section{MOISÉS MAÑAS}

Elda, Alicante, España, 1973. Vive y trabaja en Valencia, España

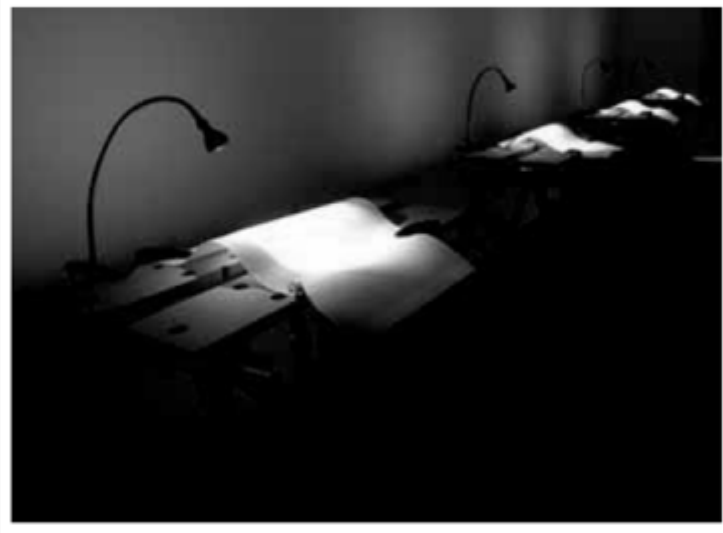

Arounda a Semantic Game, 2012. Instalación sonora luminico-mecánica controlada por ordenador

Artista multimedia, Mañas desarrolla su trabajo a través de instalaciones interactivas, arte en red, audioinstalaciones y arte electrónico desde 1996. Around: a Semantic Game es una instalación audiovisual conectada a la red y al tráfico de mensajes vía Twitter. Bajo un algoritmo sencillo y a través del azar y de los juegos de interacción y concordancia que se generan entre las palabras de los mensajes, se construye una puesta en escena analógica Icontrolada digitalmentel cercana al artelacto sonoro cinético múltiple. En este caso. bra clave que pone en marcha todo el mecanismo es around.
126 rosa.santos, Valencia PABELLÓN \& STAND 115

Figura 20 Presentación de Moisés Mañas en el Libro de artistas

Fuente: IFEMA/ARCOMadrid (2013b, p. 124).

Recordemos que, en este caso, no disponemos ni siquiera del título de las obras.

Finalmente, Mañas está entre los artistas destacados de su galería (Rosa Santos, de Valencia) y, como ocurre en el resto de los casos, la publicación no nos brinda más información sobre la instalación interactiva que encontramos en la exposición. La instalación incluida en el Libro de los artistas (véase Figura 20) recuerda a la expuesta en ARCO 2013 (Figura 13), pero no es la misma; y a pesar de que con ello consigamos entender mejor el funcionamiento de la instalación, la barrera lingüística sigue presente, ya que no se provee ninguna estrategia de apoyo lingüístico.

A modo de resumen, la Tabla 1 recoge los autores y las obras analizadas, así como las estrategias -o la ausencia de ellas- empleadas en los distintos casos, 
Tabla 1 Listado de las obras analizadas y las correspondientes estrategias de traducción empleadas

\begin{tabular}{|c|c|c|c|c|c|c|}
\hline Autor & $\begin{array}{c}\text { Título de la } \\
\text { obra }\end{array}$ & $\begin{array}{l}\text { Lengua de los ele- } \\
\text { mentos verbales } \\
\text { incluidos en la } \\
\text { obra }\end{array}$ & $\begin{array}{l}\text { Porcentaje de } \\
\text { elemento verbal } \\
\text { respecto del no } \\
\text { verbal en la obra } \\
(\%)\end{array}$ & $\begin{array}{c}\text { Estrategia } \\
\text { de traduc- } \\
\text { ción de los } \\
\text { elementos } \\
\text { verbales in } \\
\text { situ }\end{array}$ & $\begin{array}{l}\text { Apare- } \\
\text { ce en } \\
\text { soporte } \\
\text { documen- } \\
\text { tal }\end{array}$ & $\begin{array}{c}\text { Estrategia } \\
\text { de traduc- } \\
\text { ción de los } \\
\text { elementos } \\
\text { verbales } \\
\text { en soporte } \\
\text { documental }\end{array}$ \\
\hline Juan Pérez & Lacan I love U & inglés & 25 & no & sí & no \\
\hline Agirregoikoa & Marx I love U & & 25 & & & \\
\hline $\begin{array}{l}\text { Mario Ybarra } \\
\text { Jr. }\end{array}$ & $\begin{array}{l}\text {...like a cow } \\
\text { visiting a butcher } \\
\text { shop... }\end{array}$ & & 85 & & & \\
\hline Rainer Ganahl & Porca miseria & italiano & 100 & & no & \\
\hline Owanto & Où Allons Nous? & francés & 25 & & & \\
\hline Carla Filipe & $\begin{array}{l}i ? \\
i ?\end{array}$ & portugués/inglés & $\begin{array}{l}80 \\
80\end{array}$ & & sí & \\
\hline Laura Kikauka & Montaje sin tí́tulo & $\begin{array}{l}\text { alemán/inglés/trans- } \\
\text { cripción fonética del } \\
\text { inglés }\end{array}$ & 70 & & no & \\
\hline $\begin{array}{l}\text { Aleksandar } \\
\text { Duravcevic }\end{array}$ & $\begin{array}{l}\text { Tell me yours I will } \\
\text { tell you mine }\end{array}$ & inglés & 100 & & & \\
\hline Moisés Mañas & $\begin{array}{l}\text { Systematic ensem- } \\
\text { ble, around a way } \\
\text { of reading }\end{array}$ & & 90 & & sí & \\
\hline Joëlle & Systématique \#1 & francés/árabe & 35 & & no & \\
\hline Tuerlinckx & Systématique \#3 & alemán & 30 & & & \\
\hline A. R. Penck & $\begin{array}{l}\text { Die neue Illusion } \\
\text { zerstört euch }\end{array}$ & & 15 & & & \\
\hline
\end{tabular}

Fuente: Elaboración propia

tanto in situ en la feria como en los soportes documentales oficiales de ARCO (catálogo oficial y Libro de artistas).

\section{Discusión}

Los ejemplos analizados en el apartado anterior constituyen una minúscula muestra de las obras plásticas expuestas en ARCO 2013 que presentaban contenido textual. Sin embargo, en cuanto a la cuestión de si procede la figura del traductor en eventos de este tipo, nos parece que ya con esta pequeña muestra analizada ha quedado más que justificada, puesto que, en todos los casos, la experiencia se interrumpe o es incompleta si no se acompaña de un soporte lingüístico adecuado que traslade el mensaje global de la obra al espectador.

Naturalmente, cada una de ellas supone un reto distinto para el traductor y la opción de intervenir en forma directa sobre la obra queda por completo descartada; pero hoy en día, el traductor multimedia y multiplataforma cada vez tiene más recursos a su disposición para hacer accesible el contenido al público meta y el acceso a una propuesta de traducción es fácilmente aplicable con alguna de las soluciones interactivas ya presentes en la propia feria, desde códigos BIDI hasta aplicaciones móviles. 
Siguiendo la clasificación sobre las distintas estrategias de traducción que proponía Hurtado (2001), el traductor que se enfrente a la traducción de los elementos verbales presentes en estas obras deberá tener en cuenta las estrategias para la comprensión del texto original, así como las que sirven para resolver problemas de la reexpresión, como en cualquier otro tipo de traducción; sin embargo, nos parece especialmente importante la estrategia de documentación (p. 277), pues el traductor debe ser conocedor de la obra del artista en cuestión. Cada vez hay más información disponible sobre los artistas en distintas fuentes y la gran mayoría se halla en la red. Las galerías que los exhiben suelen ser una fuente de información amplia y fiable; además, en no pocas ocasiones, es el propio artista el que está disponible y es el primer interesado en que su mensaje sea correctamente interpretado.

Por otra parte, conviene recordar que puede haber varias soluciones para un problema de traducción, de modo que "las estrategias ante un mismo problema cambian según las necesidades de cada sujeto" (Hurtado, 2001, p. 278). Para establecer la mejor estrategia en cada caso, debemos ser conscientes de los distintos problemas de traducción a los que nos podemos enfrentar. Siguiendo con Hurtado, esta autora plantea los siguientes:

Problemas lingüisticos: recogen las discrepancias entre las dos lenguas implicadas. En ese sentido, las obras que hemos analizado presentan problemas lingüísticos que el traductor debe resolver.

Problemas extralingüisticos: están relacionados con cuestiones de tipo temático o cultural. En las obras analizadas, estas cuestiones pueden resultar muy evidentes, como en la obra de Agirregoikoa, la de Ganahl con su lenguaje soez (también lo es en el caso de Margolles), o en la de Kikauka, con esa especie de transcripción fonética. No obstante, estas cuestiones pueden tener un cariz más sutil, pero igualmente complejo (como sucede en la obra de Penck).

Problemas instrumentales: se originan por la dificultad en el proceso de documentación. No consideramos que este sea el caso de las obras analizadas, pues existe información accesible y concisa sobre los distintos autores y sus obras.

Problemas pragmáticos: se refieren a "los actos de habla presentes en el texto original, la intencionalidad del autor, las presuposiciones y las implicaturas" (Hurtado, 2001, p. 288). Estos son los problemas con mayor complejidad de las obras en cuestión, pues en ningún caso se trata de lenguaje denotativo, sino que los mensajes que se hallan en las obras analizadas tienen una fuerte carga connotativa que el traductor habrá de resolver es su propuesta de traducción.

De modo que tras analizar los posibles problemas de traducción presentes en los elementos verbales de las obras, el traductor podrá establecer la estrategia adecuada para resolver los casos concretos, empezando por plantearse si dicha traducción procede o no. Pero la no traducción debe ser el resultado de una estrategia expositiva ampliamente estudiada y no el resultado de una mera casualidad o del hecho de no haber considerado la presencia de los elementos verbales en las obras y de cómo estos influyen sobre el mensaje global de la obra.

\section{Conclusiones}

De acuerdo con los objetivos marcados en el presente trabajo, concluimos, en primer lugar, que tras revisar la bibliografía especializada, no existe literatura que se ocupe de la interrelación entre texto e imagen dentro del arte contemporáneo desde el punto de vista traductológico, aunque sí se aborda desde un punto de vista lingüístico (Litz, 2002; Opilowski, 2013; Stein, 2008; Ströbel, 2013) o como representación textual (Sturge, 2014, p. 130) y cultural (HooperGreenhill, 2000; Karp y Lavine, 1991). Como ya hemos mencionado anteriormente, el traductor se ha concentrado en otros aspectos de las obras plásticas, como son, por ejemplo, sus títulos (Rodríguez, 2009; Serrell, 2015) o la documentación de soporte de las distintas exposiciones (Ortega y Martínez, 2006; Ravelli 2006), incluyendo propuestas con perspectivas bastante amplias e inclusivas (Liao, 2018). 
En segundo lugar, hemos comprobado que las estrategias de localización para los elementos textuales presentes en las obras expuestas en la Feria de Arte Contemporáneo de Madrid (ARCO) y, en concreto, en las trece obras analizadas en este artículo son inexistentes. No se ha tenido en cuenta, en ningún momento, que los elementos verbales en idiomas distintos a los del público general del lugar geográfico donde tiene lugar la muestra (en este caso Madrid) puede suponer una barrera lingüística que impida al espectador tener una experiencia completa de la obra.

Dicho esto, la pertinencia de la figura del traductor en el marco específico de esta feria, como soporte a dicha localización, nos parece más que justificada.

En tercer lugar, las estrategias que proponemos para la traducción y la localización de dichos elementos textuales, de forma que resulten accesibles al espectador, se han basado en los aportes de Hurtado (2001), ya que nos permitirán abordar la traducción de las obras de forma sistematizada. De este modo, garantizaremos una experiencia completa de la obra para el espectador. También hemos tenido en cuenta la posibilidad de la no traducción, pero consideramos que el uso de esta técnica debe ser fruto de una estrategia consciente y no el resultado de la improvisación o de la desatención hacia los elementos verbales presentes en las obras.

Por último, como futuras líneas de investigación, resultaría interesante comprobar si las estrategias expositivas de la Feria de Arte Contemporáneo ARCO continúan obviando el factor lingüístico o si ha habido algún cambio en las ediciones siguientes a la analizada en el presente artículo. Es decir, proponemos hacer un análisis de la posible evolución de dichas estrategias expositivas. Igualmente, resultaría importante hacer un análisis más amplio para comprobar qué lenguas intervienen, más allá de las seis incluidas en este artículo, y ver qué estrategias expositivas se han seguido y si estas han variado en función de la lengua empleada.

Asimismo, y si bien la muestra anual de ARCo nos puede dar una idea del panorama nacional, creemos que sería sumamente ilustrativo realizar un análisis comparativo con una feria de características similares a ARCO, pero desarrollada en un ámbito internacional. En ese sentido, la feria anual Art Basel, celebrada en Basilea, es la feria de arte de mayor repercusión a nivel europeo e incluso a nivel internacional; tanto es así, que tiene una franquicia para el continente americano (Art Basel, Miami Beach) y otra para el asiático (Art Basel, Hong Kong). Comparar lo que sucede a nivel mundial entre las distintas franquicias quizás resulte muy ambicioso y complejo, pero, desde luego, creemos necesaria la comparativa a nivel europeo entre ARCO y Art Basel; de este modo, se podrían extraer conclusiones globales más allá de las casuísticas locales.

\section{Referencias}

Baker, M. (2018). Paratextual framing: Theory and methodology. Jiao Tong Baker Centre for Translation \& Intercultural Studies, Shangái. China. Recuperado de https://www.jiaotongbakercentre.org/2017/11/20/ event-paratextual-framing-theory-and-methodology/

Barthès, R. (1977). Image music text. Londres: Fontana Press.

Batchelor, K. (2018). Translation and paratexts. Londres: Routledge.

Bobes, M. C. (1989). La semiologia. Madrid: Síntesis.

Dainton, M., y Zelley, E. D. (2004). Applying communication theory for professional life: A practical introduction. Thousand Oaks, CA: SAGE Publications.

Danto, A. (1981). The transfiguration of the commonplace. A philosophy of art. Cambridge: Harvard University Press.

Espejo, B. (2014). Teresa Margolles: "Apuesto por un arte vivo y crítico". El Cultural. Recuperado de_https://www. elcultural.com/noticias/arte/Teresa-Margolles-Apuesto-por-un-arte-vivo-y-critico/5922

Galleria Enrico Astuni (2018). Rainer Ganabl. Biografia. Bolonia, 2018. Recuperado de http://www.galleriaastuni. net/artista/rainer-ganahl/

Genette, G. (1987). Seuils. París: Éditions du Seuil.

Gottfried, W. (1991). Kunst und Literatur als Gegenstand einer Theorie der Wort-Bild-Beziehungen. Skizze der methodologischen Grundlagen und Perspektiven. En: W. Harms (Ed.), Text und Bild, Bild und Text. DFGSymposion 1988 (pp. 17-26). Stuttgart: J. B. Metzler.

Heusser, M. (1993). Introduction. En Word \& Image Interactions. A selection of papers given at the second international conference on word and image. Universi- 
tät Zürich, 27-31 de agosto, 1990. (pp. 13-19). Basilea: Wiese.

Holländer, H. (1978). Bilder als Texte, Texte und Bilder. En: J. Zimmermann (Ed.), Sprache und Welterfahrung (pp. 269-300). Múnich: Fink.

Honegger, U. (2002). Wort und Bild in der visuellen Poesie des 20 Jahrhunderts. Recuperado de https://www. netzliteratur.net/urs-liz-lores.pdf

Hooper-Greenhill, E. (2000). Museums and the interpretation of visual culture. London: Routledge.

Hurtado, A. (2001). Traducción y traductología. Madrid: Cátedra.

IFEMA (2015). Un total de 212 galerias de 30 paises confirman su confianza en ARCOmadrid 2015. Recuperado de http://ifema.es/Institucional_01/ noticias/NoticiasdeFerias/ferial/INS_044105

IFEMA/ARCOMadrid (Ed.) (2013a). ARCOMadrid 2013. Madrid: ARCO.

IFEMA/ARCOmadrid (Ed.) (2013b). Libro de artistas ARCOmadrid 2013. Madrid: ARCO.

Karp, I., y Lavine, S. D. (Eds.). (1991). Exhibiting cultures: The poetics and politics of museum display. Washington: Smithsonian Institution.

Kress, G., y Van Leeuwen, T. (1996). Reading images. The grammar of visual design. Londres: Routledge.

Kunstmuseum Basel (2017). Joëlle Tuerlinckx. Basilea. Recuperado de https://kunstmuseumbasel.ch/en/ exhibitions/2016/joelle-tuerlinckx

Liao, M-H. (2018). Museums and creative industries: The contribution of translation studies. The Journal of Specialised Translation, (29), 45-62. Recuperado de https://www.jostrans.org/issue29/art_liao.pdf

Litz, C. (2002). It is unsubstantial. Zur Textualität der Kunst im 20. Jahrbundert: Duchamp, Nauman, Horn. Recuperado de http://www-brs.ub.ruhr-uni-bochum. de/netahtml/HSS/Diss/LitzChristine/diss.pdf

Nord, C. (2012). Paratranslation -A new paradigm or a re-invented wheel? Perspectives: Studies in Translatology, 20(4), 399-409. https://doi.org/10.1080/09 07676X.2012.726231

Opilowski, R. (2013). Von der Textlinguistik zur Bildlinguistik. Sprache-Bild-Texte im neuen Forschungsparadigma. Zeitschrift des Verbandes Polnischer Germanisten, 2(3), 217-225. Recuperado de http://www.ejournals. eu/ZVPG/Tom-2(2013)/Zeszyt_3_(2013)/art/2649/ http://dx.doi.org/10.4467/23534893ZG.14.018.1676
Ortega, E., y Martínez, A. B. (2006). La traducción del arte: una operación de mediación intercultural "estéticamente" condicionada. Hikma, 5, 179-199. https:// doi.org/10.21071/hikma.v5i5.6691

Ravelli, L. J. (2006). Museum texts: Communication frameworks. Londres: Routledge.

Rodríguez, M. L. (2009). Tendencias actuales en la traducción de obras de arte plástico. Entreculturas, (1), 285-299. Recuperado de http://www.entreculturas. uma.es/n1pdf/articulo15.pdf

Serrell, B. (2015). Exhibit labels: An interpretive approach. Walnut Creek: Rowman \& Littlefield Publishers.

Stein, S. (2008). Geschriebene Bilder - Kunsthistorische Vorläufer der lingualisierten Concept-Art. E-Journal für Kunst-und Bildgeschichte, (4). Recuperado de http://edoc.hu-berlin.de/18452/8078

Ströbel, K. (2013). Wortreiche Bilder. Zum Verhältnis von Text und Bild in der zeitgenössischen Kunst. Bielefeld: Transcript.

Sturge, K. (2014). Representing others: Translation, ethnography and museum. Londres: Routledge.

Totah (2018). Aleksandar Duravcevic. Biography. Recuperado de http://davidtotah.com/artists/ aleksandar-duravcevic/

32. a Bienal de São Paulo (2016). Carla Filipe. Brasil. Recuperado de http://www.32bienal.org.br/en/ participants/o/2627

Ulrichs, D. (2013). 10 Intriguing highlights from ARCO 2013, From a butcher shop to an unlit booth. Blouinartinfo. Recuperado de http://www.honorfraser. $\mathrm{com} /$ ? $=$ news\&aid $=33$

Yuste, J. (1998). Caminos semiológicos y semánticos para la traducción e interpretación del texto rabelaisiano. En T. García-Sabell Tormo et al. (Eds.). Les chemins du texte. vi Coloquio de la Apffue (Santiago, 19, 20 y 21 de febrero de 1997) (tomo 2, pp. 517-523). Universidade de Santiago de Compostela.

Yuste, J. (2001). Lecturas de la imagen para una traducción simbólica de la imaginación. En E. Real et al. (Eds.), Écrire, traduire et représenter la fête. VIII Coloquio de la APFFue (Valencia, 21, 22 y 23 de abril de 1999) (pp. 799-812). Universitat de Valencia.

Yuste, J. (2005). Desconstrucción, traducción y paratraducción en la era digital. En J. Yuste y A. Álvarez (Eds.). Estudios sobre traducción: teoría, didáctica, profesión (pp. 59-82). Vigo: Universidad de Vigo, Servizo de Publicacións. 
Yuste, J. (2015). Paratraducción: la traducción de los márgenes, al margen de la traducción. $D E L$ TA: Revista de Documentação de Estudos em
Lingüistica Teórica e Aplicada, 31, 317-347. http://dx. doi.org/10.1590/0102-445031725373379053

How to reference this article: Huertas-Abril, Cristina y Márquez-Garrido, Rocío (2020). La traducción de elementos textuales en obras de arte contemporáneo: tendencias, retos y propuestas. Íkala, Revista de Lenguaje y Cultura, 25(1), 189-208, http://doi.org/10.17533/udea.ikala.v25n01a15 